\title{
Do practice guidelines cause drug shortages? The historical example of $\beta$-blockers
}

\author{
Cite as: CMAJ 2019 September 16;191:E1029-31. doi: 10.1503/cmaj.190289
}

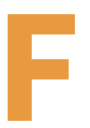

or a decade, Canada and other countries have been wrestling with shortages of drugs, defined as situations in which an authorization holder for a drug is unable to meet demand. The causes are poorly understood, and so far, solutions have been aimed at mitigation rather than prevention. This article uses a recent shortage of $\beta$-blockers to ask whether drug shortages might be provoked by good doctors dutifully following clinical practice guidelines.

\section{History}

Developed in the 1960 s as a "rational derivative" (i.e., a chemical solution to a chemical problem), the first $\beta$-blocker, propranolol, garnered the 1988 Nobel Prize for Scottish chemist James W. Black.

Since the mid-1970s, $\beta$-blockers have enjoyed enormous success, especially in the management of hypertension. According to Canada's Drug Product Database, at least 12 different molecules have been available; 2 are found on the World Health Organization's Model List of Essential Medicines. When each $\beta$-blocker went off patent, a flurry of activity followed, peaking in the mid-1990s, as generic firms created their own versions.

Since 1996, however, companies have been discontinuing $\beta$-blockers. Canadian cancellations peaked in 2014 when 15 products affecting 7 of the 12 molecules in the class were discontinued; 23 more discontinuations followed in 2017 and 2018. Combining total market entries with total exits illustrates how the discontinuations first exceeded starts in 2006 and have done so yearly since 2012 (Figure 1).

\section{Marketing}

Sixty companies have been involved in making the $12 \beta$-blockers at one time or another, with an average of 1.7 products each (range 1-7) (Supplemental Table 1 in Appendix 1, available at www.cmaj.ca/ lookup/suppl/doi:10.1503/cmaj.190289/-/ DC1). Since 1996, however, 36 companies have dropped them altogether, sometimes with failure or merger. The average duration of marketing of the discontinued products was 12.5 years (range 1-23.5 yr).

The late 1990s emerged as a period of rapid turnover, but by the early 2000s, more companies were leaving the $\beta$-blocker market than entering, a trend observed for the entire generic industry.
Of the 25 firms still engaged in marketing $\beta$-blockers, 10 have dropped at least some of their $\beta$-blocker products. The average duration of marketing is 16.8 years (range 1-38.5 yr). The average number of $\beta$-blocker products ever marketed by each of these continuing companies is 3.5 (range 1-10).

\section{Sales}

Accessing information about sales of each molecule is difficult. The Canadian Institute for Health Information (CIHI) reports data from 2002 forward, but categories and coverage vary through time. Furthermore, $\mathrm{ClHI}$ tracks expenditures only for citizens qualifying for government support,

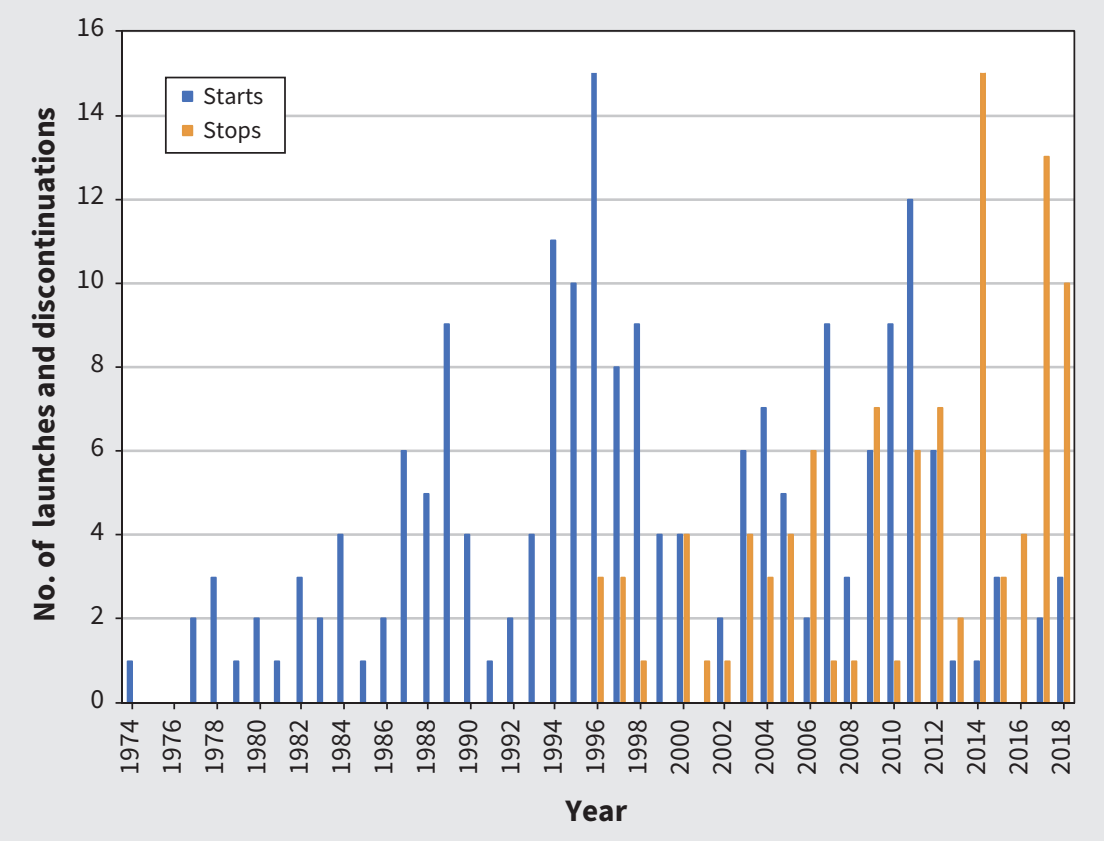

Figure 1: Launches and discontinuations of $\beta$-blockers in Canada. Source: Drug Product Database (https://health-products.canada.ca/dpd-bdpp/index-eng.jsp). 
such as seniors and people on welfare or in hospital. Nevertheless, $\mathrm{ClHI}$ data provide the only publicly available statistics on usage.

According to $\mathrm{ClHI}$, selective $\beta$-blockers were ninth in the top 10 sales of drugs prescribed to seniors in 2002; however, by 2008 , they had dropped out of the top 10 (the rank was not disclosed) and were among the fastest declining in expense for the system. In 2012, $\beta$-blockers were fourth in usage by seniors, but prices were so low that the amount spent on this class was not reported.

The 2017 report shows that at least 1.2 million Canadians still used these drugs, ranking them 11th of 100 drugs in numbers of users, but 22nd in expense. In contrast, between 2002 and 2017, markets grew for other antihypertensives: angiotensin-converting enzyme inhibitors, calcium channel blockers and angiotensin II receptor blockers. In sum, CIHI data show that $\beta$-blockers were widely sold in 2002 (and probably earlier), but from the mid-2000s, sales declined in both use and price.

\section{Shortages}

In 2010, Canadians noticed numerous shortages of many reliable drugs. The Canadian Pharmacists Association has documented the persistent and worsening problem; its 2018 survey results were recently released. Causes of shortages are poorly understood; at least 15 plausible factors have been cited. ${ }^{1}$ Health care personnel suspect the pharmaceutical industry of deliberate manipulation. Pharmaceutical manufacturers blame government regulations and inspections and difficulties obtaining raw materials. Economists and business experts cite problems with drug pricing (both too low and too high), factory closures, industry consolidation, lack of competition, and nefarious activity of American group purchasing organizations. The problem is global in scope.

From 2012, reporting on drug shortages in Canada was unreliable, being left to the pharmaceutical industry on a voluntary basis. In March 2017, reporting became mandatory. Health Canada took over the website drugshortagescanada.ca from industry, licensing its management to Bell Canada. Shortages appeared to increase, possibly an artifact of the change in reporting mechanism.

I used data gathered for an earlier paper $^{2}$ to analyze affected drug types and measure annual Canadian shortages to late 2017. About 1000 shortages appeared yearly, affecting 1250 different drug products over a 3-year period.

Reported shortages peaked in 2017 and declined slightly in 2018; however, if drugs are no longer prescribed, shortages will not be reported. The problem is not going away. At the time of writing, there are more than 1800 drug shortages.

For the $12 \beta$-blockers, 227 shortages and discontinuations were reported between March 2017 and December 2018 (Supplemental Table 1 in Appendix 1). Ten of the $12 \beta$-blockers have been in short supply, most multiple times. One (nadolol) is no longer marketed; shortages of another (pindolol) were reported in 2015-2016. The shortages of $\beta$-blockers reflect the cumulative abandoning of their manufacture (Supplemental Figure 1 in Appendix 1).

On the Drug Shortages Canada website, companies are required to supply a "reason" for each shortage; they select from a list of vague possibilities in a drop-down menu. Discontinuations are frequently ascribed to obscure "business reasons," suggesting that the product may no longer be profitable. None of the shortages have been ascribed to evidence-based medical recommendations that would suggest the drugs are not useful.

\section{Guideline impact}

For 4 decades, guidelines have been a practical response to the advent of evidence-based medicine and its emphasis on high-quality clinical trials. $\beta$-blockers once figured among the "drugs of choice" for hypertension in clinical practice guidelines. However, for at least a decade, guidelines, backed by a series of Cochrane meta-analyses, have recommended against $\beta$-blockers for older people. This practice began earlier in Canada (from 1999) than in the United States where doubts, first raised around 2003, meant that by $2014, \beta$-blockers were no longer recommended at all for older adults (Supplemental Table 2 in Appendix 1).
The supporting evidence for these recommendations is not based on clinical trials assessing adverse effects of $\beta$-blockers. Rather, it is linked to the absence of trials involving them, mortality outcomes, the presumed greater incidence of orthostatic hypotension and falls in older adults (exacerbated by the adverse effect of bradycardia), and headto-head trials showing positive results with other medications. Authors of the Cochrane reports point to the risk of bias and that most $\beta$-blocker trials examined 1 molecule only. ${ }^{3}$ Since 2003-2004, $\beta$-blockers are still recommended for hypertension in the presence of heart disease or after myocardial infarction. In 2007, however, Canadian Family Physician published a debate on their use in hypertension at any age. ${ }^{4}$

Some doubt the impact of practice guidelines. In 1998, a Canadian team, puzzled by differences in prescribing between North America and Europe, speculated that increased use of newer, alternative antihypertensives was due to marketing, not guidelines. ${ }^{5}$ Nevertheless, the findings presented in this article support recent impressions of those who believe that hypertension guidelines have had an impact in Canada, at least in terms of therapy. ${ }^{6} \mathrm{~A}$ few studies now suggest that therapeutic recommendations have gone "too far," and that $\beta$-blockers may be overlooked and unnecessarily neglected. ${ }^{7}$

The incidence of hypertension rises with age, affecting half the population older than 65 years and reaching as many as $91 \%$ of people in their eighth decade. ${ }^{8}$ Consequently, conscientious doctors observing practice guidelines will have taken an enormous number of people off $\beta$-blockers, or no longer prescribe them as first-line therapy.

The result is a tsunami change on the market. Not enough product is prescribed and sold to meet costs of manufacturing and maintaining stocks, provoking "business reasons" for discontinuation and the steady dropout of manufacturers - a precarious scenario for developing shortages.

The scarcity of an essential medicine ought logically to be a good "business reason" to continue making it. This observation raises questions about generic 
drug pricing, for which some argue that Canada pays too much, ${ }^{9}$ while others believe we pay too little and thereby exacerbate shortages through Canada's strict rules against raising prices. ${ }^{10}$

Whatever authors of clinical practice guidelines wished to accomplish, it seems doubtful that they wanted $\beta$-blockers to disappear. Are physicians inadvertently complicit in the production of drug shortages? And do practice guidelines play a role in shortages elsewhere?

\section{Jacalyn Duffin MD PhD}

School of Medicine, Queen's University, Kingston, Ont.

\section{References}

1. Causes: possible causes of the drug shortage. Available: www.canadadrugshortage.com/causes/ (accessed 2019 July 7).

2. Donnelle J, Duffin J, Pipitone J, et al. Assessing Canada's drug shortage. Commentary no. 515. Toronto: C.D. Howe Institute; June 2018. Available: www.cdhowe.org/public-policy-research/assessing -canada's-drug-shortage-problem (accessed 2019 July 7).

3. Wysonge CS, Bradley $\mathrm{H}$, Mayosi BM, et al. Betablockers for hypertension. Cochrane Database Syst Rev 2007;(1):CD002003.

4. Khan N, McAlister FA, McCormack JP. Do ß-blockers have a role in treating hypertension? Can Fam Physician 2007;53:614-7.

5. Beaulieu MD, Dufresne L, LeBlanc D. Treating hypertension. Are the right drugs given to the right patients? Can Fam Physician 1998;44:294-8, 301-2.
6. Daskalopoulou SS, Feldman RD, McAlister FA, et al. Hypertension Canada. The history of hypertension guidelines in Canada. Can J Cardiol 2019;35:582-9.

7. Mann SJ. Redefining beta-blocker use in hypertension: selecting the right beta-blocker and the right patient. J Am Soc Hypertens 2017;11:54-65.

8. Lacruz ME, Kluttig A, Hartwig S, et al. Prevalence and incidence of hypertension in the general adult population: results of the CARLA-cohort Study. Medicine (Baltimore) 2015;94:e952.

9. Morgan SG, Persaud N. New generic pricing scheme maintains high prices and risk of shortages. CMAJ 2018;190:E410-1.

10. Dave CV, Pawar A, Fox ER, et al. Predictors of drug shortages and association with generic drug prices: a retrospective cohort study. Value Health 2018; 21:1286-90.

This article has been peer reviewed.

Competing interests: None declared. 